\title{
Progress in context effect-based education: the TEEC project
}

\section{Avancées sur l'éducation par effets de contextes : le projet TEEC}

\author{
Claire Anjou ${ }^{1}$, Jacqueline Bourdeau ${ }^{1}$, Thomas Forissier ${ }^{2}$, Valéry Psyché ${ }^{1}$, Lamprini \\ Chartofylaka $^{2}$, Alain Stockless ${ }^{3}$ \\ ${ }^{1}$ Université TELUQ, Montréal, Québec, Canada anjou.claire@gmail.com, jacqueline.bourdeau@teluq.ca, \\ valery.psyche@teluq.ca, \\ ${ }^{2}$ CRREF (EA 4538), Université des Antilles, Guadeloupe, France tforissi@espe-guadeloupe.fr, \\ lamprini.chartofylaka@espe-guadeloupe.fr \\ ${ }^{3}$ UQAM, Montréal, Québec, Canada, stockless.alain@uqam.ca
}

\begin{abstract}
This paper describes the advances in the TEEC project (Technologies Éducatives pour l'Enseignement en Contexte, in English: Educational technologies for teaching in context). This multidisciplinary project is at the intersection between context in learning and educational technologies. It aims at developing and experimenting a context effects-based pedagogical model involving learners and teachers from multiple geographical contexts, collaborating on common subjects with local specificities. The project also has for objective the development of digital tools to assist and participate in the elaboration of the pedagogical projects such as a context modeller and calculator (Mazcalc), an authoring system for learning scenarios and a context aware intelligent tutoring system. The elaboration and the analyses of experiments, as well as the design and the development of tools include research in multiple fields such as Computer Supported Collaborative Learning, Artificial intelligence, Instructional Design, Intelligent Tutoring Systems, Science Education and Contextualization. Finally, the research activity relies on the Design Based Research methodology (DBR) that allows the articulation of the project between all those disciplines and stakeholders.

RÉSUMÉ. Ce document décrit les avancées du projet TEEC (Technologies Éducatives pour l'Enseignement en Contexte). Ce projet multidisciplinaire est né d'une rencontre entre la didactique contextuelle et les technologies éducatives. II vise à développer et à expérimenter un modèle pédagogique basé sur les effets de contextes, impliquant des apprenants et des enseignants de contextes géographiques multiples, collaborant sur des sujets communs mais ayant des spécificités locales. Le projet a également pour objectif le développement d'outils numériques pour assister et participer à l'élaboration des projets pédagogiques tels qu'un modélisateur-calculateur de contexte (Mazcalc), un système de création de scénarios d'apprentissage et un système de tutorat intelligent sensible au contexte. L'élaboration et l'analyse d'expérimentations, ainsi que la conception et le développement d'outils incluent des travaux de recherche dans de multiples domaines tels que l'apprentissage collaboratif assisté par ordinateur, l'intelligence artificielle, la conception pédagogique, les systèmes de tutorat intelligents, l'enseignement des sciences et la contextualisation. Enfin, l'activité de recherche repose sur la méthodologie Design-Based Research (DBR) qui permet l'articulation du projet entre toutes ces disciplines et acteurs.
\end{abstract}

KEYWORDS. Context effect, education, Instructional Design, collaboration, Design-Based Research.

MOTS-CLÉS. Effet de contexte, éducation, design pédagogique, collaboration, Design-Based Research.

\section{Introduction and Theoretical Framework}

In the field of education, the term "context" has many definitions and often depends on the discipline in which it is studied. In science learning, context is generally described as the student's physical environment, and context-based approaches link the learning to real world situations to allow students to better understand the possible application of what they learn [1]. Context is also involved in cognitive psychology work about knowledge. The relationships between context and cognition give the context either an internal or an external nature [2]. In the first case, it belongs to an individual and occupies a prominent place in the representation that the individual constructs for 
him-herself regarding the situation in which s-he is involved. In the other case, the context is related to elements external to the individual. The external context participates in the construction of learners' conceptions i.e., learners' internal context, which is situated in the social, cultural, institutional, historical, as well as in the geographical and environmental contexts and cannot be studied separately from the latter.

The impact of context on teaching and learning is well recognized. The distinction between external and internal contexts is of major importance in the studies regarding context effects [3]. The term "context effect" was created to characterize the phenomena occurring in a didactic situation in which a gap or a difference between multiple contexts is highlighted. According to Forissier [3], these phenomena, so far perceived as obstacles, can support learning and can be used as a tool for teaching. Toward this goal, he developed the context effects-based pedagogical approach. This approach involves learners living in different geographical places and relies on investigative works and collaborations. It allows students to realise the contextuality of their conceptions and provides the opportunity for learners to understand diversity and to enrich their knowledge.

Zimmermann, Lorenz, et al. [4] suggest defining context along five dimensions: identity, time, space (place), activity, and relationship. In line with the ambition to parameter context, the idea to model it for teaching and learning purpose emerged and led towards the development of the CLASH model [3]: two students living in two distinct contexts possess conceptions on the same object that are constructed according to their respective contexts. As a result, their conceptions of this same object are different. The modeling of a student's external context regarding a given object can allow to identify context gaps and lead to the prediction of learning themes on which context effects can emerge. Owing to that prediction, learning scenarios can be designed based on context effects.

\section{TEEC Project}

The TEEC project1 is the result of a collaboration between seven laboratories in three geographical locations: Guadeloupe, continental France and Quebec. It started in 2016 with the following objectives: (1) build and test a teaching model based on the emergence of context effects in multiple domains and at various academic levels; (2) characterize context effects phenomena in the experiments thanks to multiple cross-methodologies; (3) develop a digital tool that can model contexts and predict the emergence of context effects; (4) develop digital tools for the design and development of Context Aware Intelligent Tutoring System (CAITS).

The project also aims to validate the following hypotheses: (1) a pedagogical scenario built according to the gaps between two external contexts allows a conceptual change in learners' mind; (2) context modelling based on context parameters' characterisation can allow calculating the gap between two contexts; (3) the prediction of context effects through contexts modelling and calculation will be validated by the implementation of learning scenarios and by assessing students' conceptions throughout experiments.

\section{Methodology}

The Design-Based Research (DBR) methodology has proven to be the appropriate methodology for the TEEC project. It is a micro-systemic methodology that supports both the verification of hypotheses and the testing of innovative instrumentation through iterations. The design component of this methodology provides methods in order to improve the learning design along with experimenting it. This methodology also emphasizes the collaboration between research and practice [5]. Five experiments in various domains were conducted to test the CLASH model,

\footnotetext{
${ }^{1}$ https://teec.teluq.ca/fr/
} 
between the two contrasted contexts of Quebec and Guadeloupe. At the same time, the Mazcalc software was developed to calculate the gap between two external contexts based on various parameters and themes [6]. Based on the results of the Mazcalc calculation, learning scenarios can be designed. The learning scenarios have to be elaborated collaboratively between the actors of both contexts. They also have to specify learning activities based on local investigations such as field experiments and lab work, and they have to include synchronous and asynchronous exchanges between learners, in order to optimize the emergence of context effects [3]. An advanced tool called "Scenarisator" proposes a modelling of the learning design specific to context-based collaborative learning, that helps teachers and instructional designers in their collaborative design project. Also, works on the design and development of a context aware intelligent tutoring system and of an authoring system for the designing of learning scenarios based on the Mazacalc is underway, all along with the experimental activities.

The experiments allow the collection of various data such as video recordings of synchronous exchanges and of aside activities, asynchronous exchanges on the Edmodo platform ${ }^{2}$, pre and posttest questionnaires, learners' productions, teachers and learners interviews, and diverse organisational materials. Multiple types of analyses were conducted in diverse fields. In the first hand, emotion facial recognition [7] and interactional analysis [8] were coupled to characterize context effects. Didactic analysis about the evolution of conceptions and about learning competencies of context effects-based pedagogies $[9,10]$ were carried out. Finally, analysis in the domain of educational technologies [10] has been conducted. In parallel, the design of authentic instrumentations was developed, aiming at facilitating the teaching practices with context effects and the research owing to global DBR reflection on the project, discussions with TEEC actors, ontologies and literature review. The ultimate goal is the development of a Context-Aware Intelligent Tutoring System (CAITS). The current efforts aim at constructing such a system with two interfaces, one for an author and one for a learner, that both rely on the Mazcalc [3].

\section{Preliminary results}

The interactional analyses merged with the emotional facial recognition carried out on the five experiments allow to specify the modalities of the context effect emergence, the way it manifests itself and its consequences on the interaction. The interactional analyses have associated the context effect to a "Grounding" phenomenon in which learners attain mutual understanding in dialogue. By this process, learners can develop shared conceptions during an interaction. Due to the initial divergence in learners' conceptions, the grounding is interrupted by a clash moment related to a rupture in the mutual understanding. The interactional sequence of the context effect takes place as follows: (a) questioning (from context 1), (b) set of unstructured phases of explanations, disagreement, misunderstanding and argumentations (between both contexts), and (c) mutual agreement and understanding (from both contexts), [8]. Facial recognition analyses, realized by J. Gonzalez and L. Prevost (emotional computing specialists) have characterized the context effect as the sudden understanding of a concept by the learners associated with an "Eureka" effect. These analyses of learners' faces during the interactions showed emotional patterns resulting in a succession of emotional states of frustration (frown), astonishment (interjection expressed with "Ha!") and joy. The superposition of the two types of analyses revealed a match between the emotional moment of joy and of mutual agreement allowing for a good qualification of the context effect according to these two dimensions.

The content analysis of online asynchronous discussions between learners was conducted with the exchanged messages from the Edmodo platform. Messages obtained from the platform were characterized as task-related, group-related, and off-task topics. Several differences between the

\footnotetext{
${ }^{2}$ https://new.edmodo.com/
} 
messages exchanged on two TEEC experiments have been identified [10]. It is worth mentioning that the richness of the exchanges between participants also depends on many additional elements rather than the motivation and the engagement of participants. Nevertheless, three main points influencing the asynchronous interactions between the participants have been identified: a) the level of expertise of children and teachers, b) technological resources available for use in every school and c) internet connection in classrooms. The Edmodo platform has proven to provide a secure digital environment for young participants to contribute at their own pace to the discussion, with no time constraints (as opposed to videoconferences). Individually or in small groups, the incorporation of educational social networks can enhance the communication of participants. To improve the use of Edmodo as an asynchronous tool for collaboration, it is recommended to provide beforehand training and support to the participants and to the teaching staff.

The analyses resulting from the pre and post-test questionnaires validate the idea that the design of a pedagogical scenario based on context effects can promote learning and enrich learners' conceptions [9]. Studying the same object by confronting different contexts allows the increase of learners' knowledge about the given object. Learners' conceptions move from acontextual and spontaneous knowledge to multicontextual knowledge. This approach allows students to identify what is fully relevant to the concept under study, while at the same time perceiving how this object adopts specific characteristics depending on the context in which it is studied. It is fundamental to insist on the initial postulate of the research, which is based on the fact that the confrontation of contexts, in order to be effective, is not done in an 'artificial' way (presentation of different contexts by the teacher) but is anchored in the contrasting realities of the learners, who thus become part of a motivating investigative approach where all points of view are possible. To do so, the learning scenario must be designed in such a way that it supports the explicit discussion about contexts. A shared task with a common production between the learners from the two contexts is a necessary condition for collaboration with learning potential [8].

The analysis of the semi-directive interviews conducted with teachers show the support of digital technology for learners' motivation, for the development of relationships between actors and for the development of learners' skills. From a learning point of view, teachers emphasize the contribution of this type of project in the development of students' communication skills. From a technical point of view, teachers gave feedback on their experiences on the tools, the materials and the general organisation of the project. It has been noticed that such projects create additional workload for teachers and must be lightened.

The development of an intelligent authoring system, including contextual parameters, would facilitate the design of learning scenarios based on context effects. Also, it would improve the collaboration between the teachers of the two contexts, and between the teachers and the researchers. The context calculator Mazcalc has been designed and preliminary results have been published [6]. However, the available tool during the experiment's implementation was a nonfunctional prototype, not yet developed. It has not been fully used because of its complexity in the actual state (providing gap values on contextual parameters regarding the studied object and not concrete advice). This emphasizes the need of developing a support tool, with a complex consulting intelligence considering multiple parameters: regarding the object of study and its respective contexts, but also setting up information on the context of the pedagogical project (age of the learners, institutional constraints etc...). The efforts now need to focus on the design of the context aware intelligent tutoring system, based on learner' context but also on the context of the learning object.

\section{Conclusion and future work}

For now, the results of works carried out in the TEEC project have provided a complete characterisation of what a context effect is and of how it arises. The learning design needs to be 
better framed in order to provide a real collaboration between students. In addition to the modelisation of learners' external context, related to the studied object, the pedagogical context must be considered thanks to another parameter modeling, embedded in the authoring system. The asynchronous exchanges platform has proven to provide a good opportunity for the collaboration and must be made more accessible to the learners and teachers. Finally, future work should help teachers and instructional designers to reach a common agreement, allowing to collect data aiming at identifying more precisely the acquired knowledge and the developed competencies. The results could be included in the CAITS and improve its intelligence.

The DBR methodology has been explicitly formulated in the TEEC project and given the systemic and holistic nature of this methodology, the results of previous experiments and of future ones can be used to nurture the development of the digital tools. Those tools have to be continuously improved and adjusted as a result of feedback collected from the experiments and analyses undertaken. The analysis methodology developed during the TEEC project may also be applied to previous and future experiments, and can be improved as expected by the DBR methodology.

The CLASH model has proven to be adaptable to different age groups and in multiple disciplines, but until 2020, all experiments carried out were conducted between the two same geographical areas: Quebec and Guadeloupe. The new hypothesis to be explored relates to the adaptability of our pedagogical model to other geographical areas and with multiple languages. The idea of adding a third location is also an avenue to be pursued.

\section{Acknowledgment and credits}

The TEEC project is funded by two research agencies: the Agence Nationale de la Recherche (ANR) from France and the Fond de Recherche du Québec, Société et Culture (FRQSC). The TEEC team wants to give special thanks to researchers, research assistants, collaborators, and especially to teachers who participated in the project. Thanks to Sacha Luccioni for her english proofreading of the text.

\section{Bibliography}

[1] King, D. New perspectives on context-based chemistry education: Using a dialectical sociocultural approach to view teaching and learning. Studies in Science Education, 2012. 48, 51-87, http://eprints.qut.edu.au/48956/.

[2]Bazire, M. and Brézillon, P., Understanding Context Before Using It, in Modeling and Using Context: 5th International and Interdisciplinary Conference, CONTEXT 2005, Paris, France, July 5-8, 2005. Proceedings, Dey, A., et al., Editors. 2005, Springer Berlin Heidelberg: Berlin, Heidelberg. p. 29-40. https://doi.org/10.1007/11508373_3.

[3] Forissier, T., et al., Modeling Context Effects in Science Learning: The CLASH Model, in Modeling and Using Context: 8th International and Interdisciplinary Conference, CONTEXT 2013, Annecy, France, October 28 -31, 2013, Proceedings, Brézillon, P., Blackburn, P. and Dapoigny, R., Editors. 2013, Springer: Berlin, Heidelberg. p. 330-335. https://doi.org/10.1007/978-3-642-40972-1_25.

[4]Zimmermann, A., Lorenz, A., and Oppermann, R. An operational definition of context. in International and Interdisciplinary Conference on Modeling and Using Context. 2007. Springer.

[5] Bourdeau, J., The DBR methodology for the study of context in learning, in Modeling and Using Context. CONTEXT 2017. Lecture Notes in Computer Science, Brézillon, P., Turner, R. and Penco, C., Editors. 2017, Springer. p. 541-553. https://doi.org/10.1007/978-3-319-57837-8_44.

[6] Anjou, C., et al. Elaborating the Context Calculator: A Design Experiment in Geothermy. in International and Interdisciplinary Conference on Modeling and Using Context. 2017. Springer.

[7] Piot, M., et al., Joint analysis of verbal and nonverbal interactions in collaborative E-learning. 2019. 
[8]Le Bail, C., et al., Grounding and knowledge elaboration across cultural and geographical contexts: An exploratory case study. Learning, Culture and Social Interaction, 2021. 28: p. 100477. https://hal.telecomparis.fr/hal-03044452.

[9] Chartofylaka, L., et al., Il était une fois des contes en contextes: retour sur une expérimentation au primaire en Guadeloupe et au Québec. Contextes et didactiques, 2018(11): p. 67-108. https://journals.openedition.org/ced/1014.

[10] Chartofylaka, L., et al., Sharing contextual knowledge information via asynchronous distance learning: Insights from a context-based research project in primary schools. Médiations et médiatisations - Revue internationale sur le numérique en éducation et communication, 2019. https://hal.archives-ouvertes.fr/hal02390201. 